
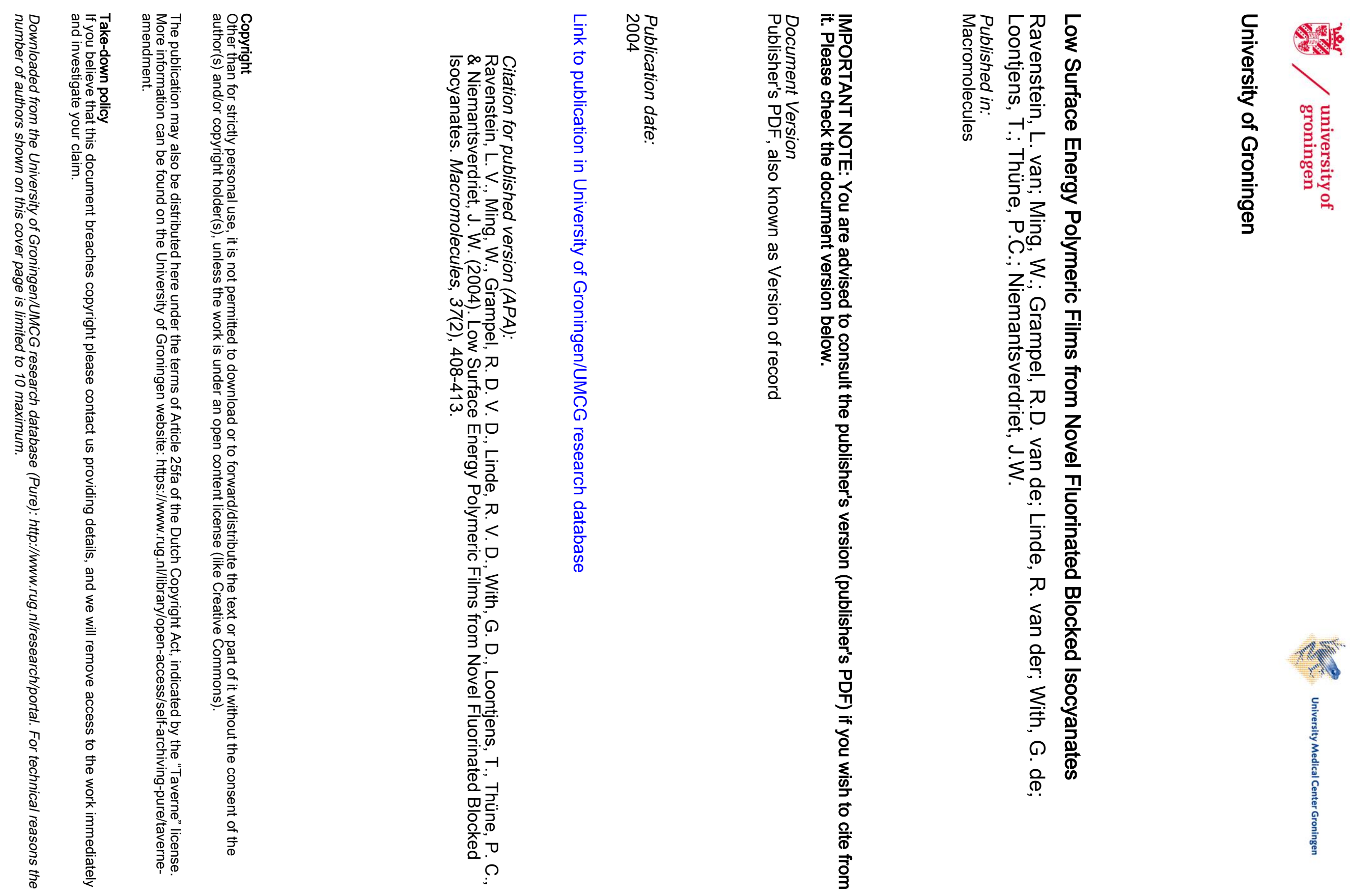


\title{
Low Surface Energy Polymeric Films from Novel Fluorinated Blocked Isocyanates
}

\author{
L. van Ravenstein, ${ }^{\dagger}$ W. Ming, ${ }^{*, \dagger}$ R. D. van de Grampel, ${ }^{\dagger}$ R. van der Linde, ${ }^{\dagger}$ \\ G. de With, ${ }^{\dagger}$ T. Loontjens, ${ }^{\ddagger}$ P. C. Thüne, ${ }^{\S}$ and J. W. Niemantsverdriet ${ }^{\S}$ \\ Lab of Coatings Technology and Schuit Institute of Catalysis and Dutch Polymer Institute, \\ Eindhoven University of Technology, P.O. Box 513,5600 MB Eindhoven, The Netherlands, \\ and DSM Research, P.O. Box 18,6160MD Geleen, The Netherlands
}

Received September 3, 2003; Revised Manuscript Received November 12, 2003

\begin{abstract}
Polymeric films with surface energies as low as $10 \mathrm{mN}$ m were prepared from a mixture of a hydroxyl-end-capped solventless liquid oligoester (SLO), a blocked polyisocyanate, and a novel fluorinated blocked isocyanate $\left(\mathrm{F}_{n} \mathrm{~B}-\mathrm{NCO}\right.$; the ratio of the fluorinated tail and the caprolactam blocking group: 1: 1), with less than $4 \mathrm{wt} \%$ of fluorine in the films. The curing temperature demonstrated a significant effect on the reaction rate and the film wettability: a higher curing temperature led to a less significant surface enrichment of fluorine, especially at a low F content $(<2 \mathrm{wt} \%)$, due to the fast immobilization of the cross-linked networks. The mixtures had excellent stability below the deblocking temperature $(\sim 140$ ${ }^{\circ} \mathrm{C}$ ) of the blocked isocyanates, which allowed the determination of the diffusion coefficients of fluorinated species in the reaction mixtures by pulsed field gradient $(\mathrm{PFG}) \mathrm{NMR}$. The well-defined $\mathrm{F}_{n} \mathrm{~B}-\mathrm{NCO}$ enabled an easy and accurate adjustment of the fluorine concentration, making this approach practically attractive and efficient to prepare low surface energy films by using small amounts of fluorinated species.
\end{abstract}

\section{Introduction}

Fluoropolymers offer a wide range of interesting properties, such as low wettability (water bil repellency) and low coefficients of friction. ${ }^{1}$ These properties are basically surface properties, and it is, therefore, unnecessary to have the expensive fluorine in the bulk. The good water bil repellency is especially due to the low surface energy of the fluorinated films, and there has been a considerable amount of interest to prepare fluorinated films. ${ }^{2}$ Self-stratification strategies provide an excellent opportunity to create coatings in which desired surface and bulk properties are well-balanced. In such an approach, only a very small quantity of fluorinated species is needed to provide a surface with low surface energy. The fluorinated species would migrate toward the air film interface to minimize the interfacial energy. ${ }^{\text {bb,c,e,f }}$

We have recently developed low surface energy crosslinked films on the basis of a partially fluorinated hydroxyl-end-capped solventless liquid oligoester (SLO, Scheme 1), either thermally cured ${ }^{3}$ with a polyisocyanate or photocured ${ }^{4}$ after the introduction of acrylic double bonds. The addition of $1-1.5 \mathrm{wt} \%$ of fluorine could reduce the surface energy from 45 to $20-30 \mathrm{~m} \mathrm{~N} /$ $\mathrm{m} \cdot{ }^{3,4}$ Much stronger surface segregation of fluorinated species was obtained by using partially fluorinated polyisocyanates (the lowest surface energy reaching 10 $\mathrm{mN} / \mathrm{m}$ ), owing to the enhanced diffusivity of fluorinated polyisocyanates in comparison with fluorinated oligoesters. ${ }^{5,6}$ During the partial fluorination, ${ }^{3,5,7}$ the nonfluorinated components were in large excess compared to the fluorinated molecules, limiting the maximum

\footnotetext{
* Corresponding author: Fax 31-40-2445619, e-mail W.Ming@tue.nl.

${ }^{\dagger}$ Lab of Coatings Technology, Eindhoven University of Technology.

${ }^{\ddagger}$ DSM Research

\$ Schuit Institute of Catalysis and Dutch Polymer Institute, Eindhoven University of Technology.
}
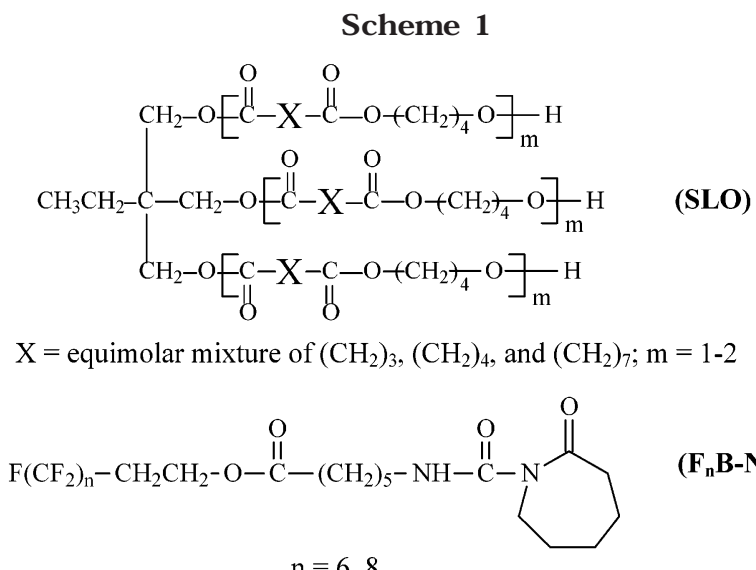

( $\left.\mathrm{F}_{\mathrm{n}} \mathrm{B}-\mathrm{NCO}\right)$

amount of fluorine that can be incorporated into the films to relatively low levels; the low levels of fluorine content may not sustain the low film wettability in applications where mechanical abrasion is present. Another weak point in the partially fluorinated oligoesters polyisocyanates systems is that the extent of fluorination for individual molecules cannot be accurately controlled. Besides, because of the high reactivity between isocyanate and hydroxyl groups, the stability of the reaction mixtures is another issue to be improved, as far as any practical applications are concerned.

In this paper we report a convenient yet novel way of synthesizing fluorinated blocked isocyanates with a well-defined structure, which allowed an easy and accurate approach to prepare low surface energy films on the basis of polyurethane systems. The cross-linking reactions were monitored by attenuated total reflectance (ATR) FTIR. Diffusion coefficients of the fluorinated species in the reaction mixtures were measured by PFG NMR. The fluorine enrichment in the top surface of the films was examined by contact angle measurements and X-ray photoelectron spectroscopy (XPS). Temperature 
effects on both cross-linking and film wettability were investigated.

\section{Experimental Section}

Materials, Synthesis, and Film Preparation. The synthesis of a solventless liquid oligoester (SLO, Scheme 1) was detailed elsewhere. ${ }^{3,7}$ The $M_{\mathrm{n}}$ for this oligoester was estimated to be 914 from ${ }^{1} \mathrm{H}$ NMR. The molar a mount of hydroxyl groups in $1 \mathrm{~g}$ of the oligoester was $3.56 \times 10^{-3} \mathrm{~mol}$ as determined by titration. The majority of the cross-linker was Desmodur BL3272 (hexamethylene diisocyanate polyisocyanurate blocked by caprolactam) from Bayer.

The perfluoroalkyl-end-capped caprolactam-blocked isocyanates $\left(\mathrm{F}_{n} \mathrm{~B}-\mathrm{NCO}\right)$ were synthesized via a one-step reaction ${ }^{8,9}$ between $N, N$-carbonyl biscaprolactam (CBC, ALLINCO, a gift from DSM Research) and an equal molar amount of a perfluoroalkyl alcohol, $\mathrm{F}\left(\mathrm{CF}_{2}\right)_{n} \mathrm{CH}_{2} \mathrm{CH}_{2} \mathrm{OH}(n=6$ or 8, gifts from Clariant $\mathrm{GmbH}$ ), under a dry $\mathrm{N}_{2}$ atmosphere at $125^{\circ} \mathrm{C}$ for 5 $\mathrm{h}$ and catalyzed by $\mathrm{MgBr}_{2}$ (1\% of the total weight of the reactants). The obtained $\mathrm{F}_{n} \mathrm{~B}-\mathrm{NCO}$ were purified by recrystallization in ethyl acetate. The structures of $\mathrm{F}_{n} \mathrm{~B}-\mathrm{NCOs}$ were examined by ${ }^{1} \mathrm{H},{ }^{19} \mathrm{~F}$, and ${ }^{13} \mathrm{C}$ NMR on a Varian 400 spectrometer at $25^{\circ} \mathrm{C}$ with $\mathrm{CDCl}_{3}$ as the solvent.

In the reaction mixtures comprising $\mathrm{SLO}, \mathrm{F}_{n} \mathrm{~B}-\mathrm{NCO}$, and BL-3272 the overall OH blocked-NCO molar ratio was maintained slightly greater than 1 to ensure the complete conversion of the blocked NCO groups. The ratio of $\mathrm{F}_{n} \mathrm{~B}-\mathrm{NCO}$ to BL3272 was varied to obtain different fluorine contents in the films. These mixtures did not undergo any reactions below 140 ${ }^{\circ} \mathrm{C}$. Thin films were applied on clean aluminum panels and then cured at $150-200^{\circ} \mathrm{C}$ for $1-3 \mathrm{~h}$. The thickness for dry films was found to be about $20 \mu \mathrm{m}$, as measured using a TwinCheck thickness gauge by List-Magnetic GmbH.

Techniques. Contact angles were measured with deionized water and hexadecane ( $>99 \%$, Merck) on a contact angle microscope (G 10, Krüss, Hamburg). In-situ IR spectra were recorded under dry $\mathrm{N}_{2}$ atmosphere on a BioRad Excalibur spectrophotometer equipped with a mercury-cadmium-telluride (MCT) detector, a MKII Golden Gate heated diamond $45^{\circ}$ ATR top plate (Specac Ltd., England), and a 3000 series high stability temperature controller (Specac). Reactive mixtures of BL-3272and SLO were deposited on the diamond unit and cured at elevated temperatures. Spectra (eight scans per spectrum at a resolution of $4 \mathrm{~cm}^{-1}$ ) were collected each minute until the completion of the cross-linking reaction. XPS measurements were performed on a VG-Escalab spectrometer using an aluminum anode ( $\mathrm{Al} \mathrm{K \alpha}=1486.3 \mathrm{eV}$ ) operating with a background pressure of $2 \times 10^{-9} \mathrm{mbar}$. A takeoff angle of $90^{\circ}$ (between the film surface and the axis of the analyzer lens) was used, corresponding roughly to a sampling depth of $\sim 8$ $\mathrm{nm} .{ }^{10}$ Spectra were recorded within $2 \mathrm{~min}$ in order to minimize radiation damage of the sample. Curve fitting was done with Casa XPS version 2.19 software.

The diffusion coefficients $\left(D_{\mathrm{c}}\right)$ of fluorinated species in the reaction mixture of SLO, $\mathrm{F}_{n} \mathrm{~B}-\mathrm{NCO}$, and $\mathrm{BL}-3272$ at 60,80 , and $100^{\circ} \mathrm{C}$ (below the deblocking temperature, ca. $140^{\circ} \mathrm{C}$, of blocked isocyanates) were determined by pulsed field gradient (PFG) NMR. ${ }^{11-13}$ Special coaxial NMR tubes were used to separate the locking agent (DMSO- $d_{6}$ ) from the reaction mixture to be analyzed. ${ }^{19} \mathrm{~F}$ NMR spectra were recorded on a Varian 500spectrometer. The peak at $-85.8 \mathrm{ppm}\left(\mathrm{CF}_{3}\right.$, Figure 2) was chosen for further analysis. A series of magnetic field gradient pulses $G_{i}(\mathrm{~T}$ m) were applied on the sample, resulting in attenuated signal intensities $S\left(G_{i}\right)$. The relation between $D_{\mathrm{c}}$ and attenuated signal intensities is as follows:

$$
\ln \frac{S\left(G_{i}\right)}{S\left(G_{\mathrm{O}}\right)}=-D_{\mathrm{c}} \gamma^{2} \delta^{2}(\Delta-\delta ß)\left(G_{i}^{2}-G_{\mathrm{O}}^{2}\right)
$$

where $S\left(G_{i}\right)$ is the signal intensity at $G_{i}, G_{i}$ the strength of the field gradient, $\gamma$ the gyromagnetic ratio, $\delta$ the length of the diffusion gradient, and $\Delta$ the gradient pulse interval. $D_{c}$

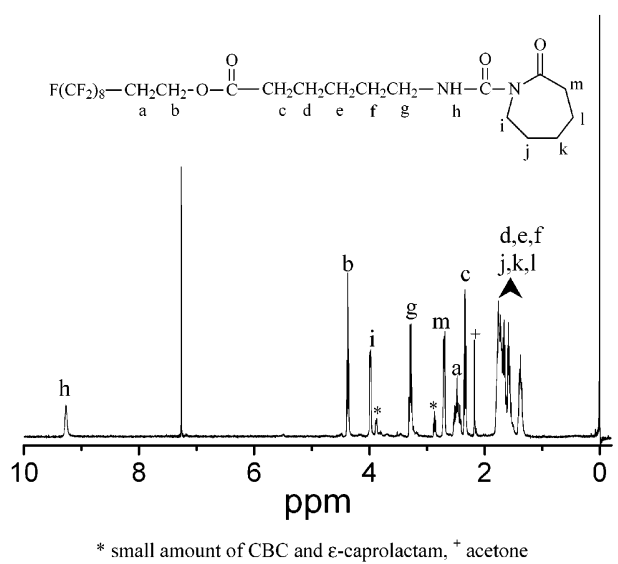

Figure 1. ${ }^{1} \mathrm{H}$ NMR spectrum of $\mathrm{F}_{8} \mathrm{~B}-\mathrm{NCO}$.

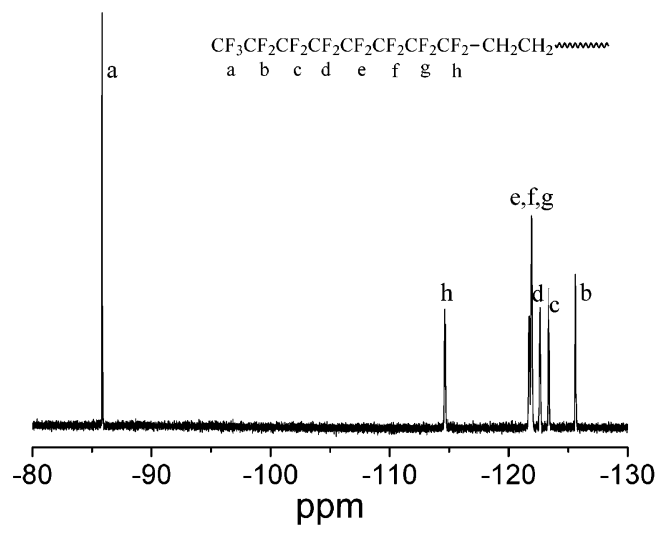

Figure $2{ }^{19} \mathrm{~F}$ NMR spectrum of $\mathrm{F}_{8} \mathrm{~B}-\mathrm{NCO}$.

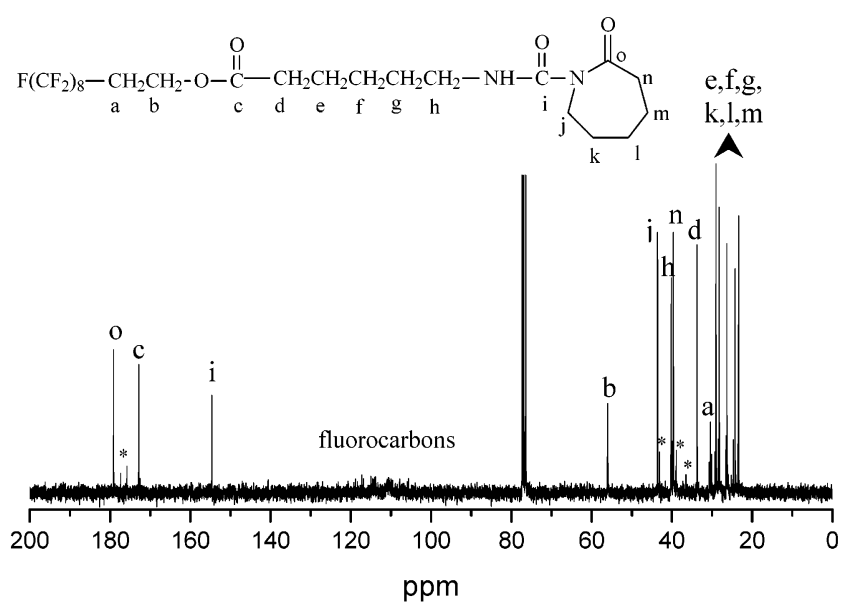

* small amount of $\mathrm{CBC}$ and $\varepsilon$-caprolactam

Figure $3{ }^{13} \mathrm{C}$ NMR spectrum of $\mathrm{F}_{8} \mathrm{~B}-\mathrm{NCO}$.

can be determined from (1). The use of ${ }^{19} \mathrm{~F}$ NMR allows the exclusive analysis of $D_{\mathrm{c}}$ of $\mathrm{F}_{n} \mathrm{~B}-\mathrm{NCOs}$.

\section{Results and Discussion}

Synthesis of $\mathbf{F}_{n} \mathbf{B}$-NCOs. The $\mathrm{F}_{n} \mathrm{~B}-\mathrm{NCO}$ were synthesized via a one-step reaction between $\mathrm{CBC}$ and an equal molar amount of $\mathrm{F}\left(\mathrm{CF}_{2}\right)_{n} \mathrm{CH}_{2} \mathrm{CH}_{2} \mathrm{OH}$ in high yields. ${ }^{89}$ The structure of $\mathrm{F}_{n} \mathrm{~B}-\mathrm{NCOs}$, with a perfluoroalkyl group on one end and a caprolactam blocking group on the other, was confirmed by NMR analyses. Shown in Figures $1-3$ are ${ }^{1} \mathrm{H},{ }^{13} \mathrm{C}$, and ${ }^{19} \mathrm{~F}$ NMR spectra for $\mathrm{F}_{8} \mathrm{~B}-\mathrm{NCO}$, which correspond well to its molecular structure. For instance, in Figure 1, the integrals of peaks $b$ and $m$ (or $i$ ) are the same, indicating a 1:1 ratio 


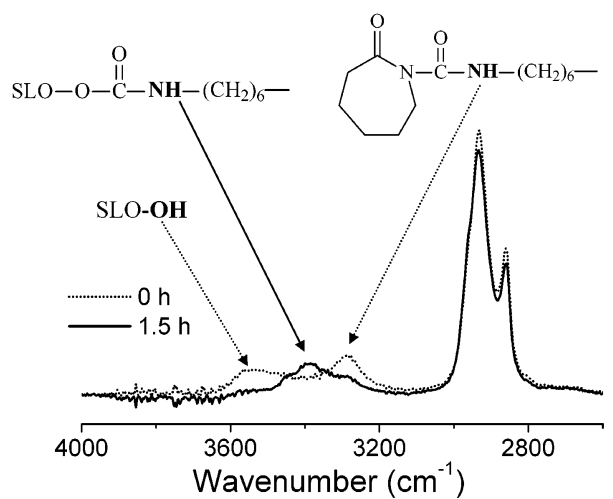

Figure 4. IR spectra of the reaction mixture of SLO and BL3272 at the beginning of the reaction and after $1.5 \mathrm{~h}$ reaction at $160^{\circ} \mathrm{C}$.

between the perfluoroalkyl group and the caprolactam blocking group in $\mathrm{F}_{8} \mathrm{~B}-\mathrm{NCO}$.

The well-defined structure of the fluorinated blocked isocyanates enabled an easy and accurate adjustment of the fluorine content in the films. The majority of the cross-linker was a nonfluorinated blocked polyisocyanate cross-linker (Desmodur BL-3272). The blocked (poly)is ocyanates rendered the reaction mixtures stable up to $140^{\circ} \mathrm{C}$, which in turn would allow the determination of diffusion coefficients of the fluorinated species in the mixture of $\mathrm{F}_{n} \mathrm{~B}-\mathrm{NCO}, \mathrm{BL}-3272$ and SLO at a temperature below $140^{\circ} \mathrm{C}$, as shown below .

Reactions between SLO and Blocked Polyisocyanate. The reactions between caprolactam-blocked isocyanates and hydroxyls lead to the formation of a urethane (carbamate) linkage via an addition-elimination mechanism while releasing $\epsilon$-caprolactam, which has been well documented in literature. ${ }^{14}$ The crosslinking reactions between the hydroxyl groups of SLO and BL-3272were monitored by ATR-FTIR at 150, 160, and $180^{\circ} \mathrm{C}$. IR spectra of the reaction mixture of SLO and $\mathrm{BL}-3272$ at the beginning of the reaction and after $1.5 \mathrm{~h}$ at $160{ }^{\circ} \mathrm{C}$ are shown in Figure 4. The $\mathrm{OH}$ stretching peak $\left(3530 \mathrm{~cm}^{-1}\right)$ from SLO and the $\mathrm{NH}$ stretching peak $\left(3290 \mathrm{~cm}^{-1}\right)$ from BL-3272disappeared or decreased significantly after $1.5 \mathrm{~h}$ reaction, and a new $\mathrm{NH}$ stretching peak $\left(3400 \mathrm{~cm}^{-1}\right)$ emerged due to the formation of the urethane bond.

The disappearance of the $\mathrm{OH}$ stretching peak at 3530 $\mathrm{cm}^{-1}$ of the SLOwas used as an indication of the extent of the reaction. The $\mathrm{C}=\mathrm{O}$ peak at $1690 \mathrm{~cm}^{-1}$ of the is ocyanurate ring remained unchanged and was thus taken as an internal reference. The conversion of $\mathrm{OH}$ could be derived from the decrease of the $\mathrm{OH}$ peak. Figure 5 shows the pronounced effect of the reaction temperature on the $\mathrm{OH}$ conversion: it took only $20 \mathrm{~min}$ at $180^{\circ} \mathrm{C}$ while about $3 \mathrm{~h}$ at $150^{\circ} \mathrm{C}$ to reach a similar extent of $\mathrm{OH}$ conversion (about 95\%). The cure half-life time for the reactions at 150,160 , and $180^{\circ} \mathrm{C}$ was found to be about $7.5,33.3$, and $64.5 \mathrm{~min}$, respectively, according to an asymptotic regression exponential fitting for the data in Figure 5. The reaction at $200{ }^{\circ} \mathrm{C}$ would proceed even faster than at $180^{\circ} \mathrm{C}$ (data were not collected due to the operation temperature limit for the ATR unit). The addition of a small amount of $\mathrm{F}_{n} \mathrm{~B}$ NCO did not show significant effect on the cross-linking reactions.

Measurement of Diffusion Coefficient $\left(D_{c}\right)$ of Fluorinated Species in the Reaction Mixture. Below the deblocking temperature (ca. $140{ }^{\circ} \mathrm{C}$ ) of the

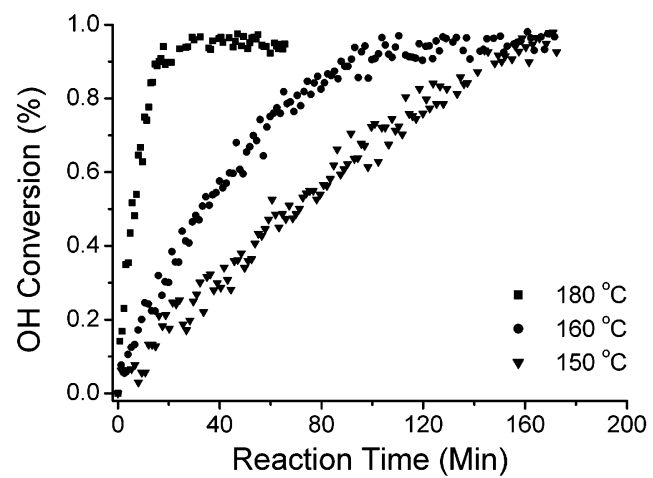

Figure 5. Temperature effects on the $\mathrm{OH}$ conversion during the reaction between SLO and BL-3272 from ATR-FTIR studies.

blocked isocyanates used in this study, the reaction mixture of SLO, $\mathrm{F}_{n} \mathrm{~B}-\mathrm{NCO}$, and BL-3272 was stable, which allowed us to determine the $D_{c}$ of the fluorinated species in the reaction mixture at a temperature below $140{ }^{\circ} \mathrm{C}$ by using PFG NMR. ${ }^{19} \mathrm{~F}$ NMR was used to exclusively determine the $D_{\mathrm{c}}$ of the fluorinated species.

The attenuated signal of $\mathrm{CF}_{3}(-85.8 \mathrm{ppm}$, Figure 2) of $\mathrm{F}_{8} \mathrm{~B}-\mathrm{NCO}$ in a mixture of SLO, $\mathrm{F}_{8} \mathrm{~B}-\mathrm{NCO}$, and BL3272 (containing 3.8wt \% of F) was collected at different temperatures. Figure 6 shows the attenuated signals of the $\mathrm{CF}_{3}$ peak under different field gradients at 100 ${ }^{\circ} \mathrm{C}$. $D_{\mathrm{c}}$ can be obtained from the slop of the plot of $\ln$ $\left[S\left(G_{i}\right) S\left(G_{0}\right)\right]$ against $\gamma^{2} \delta^{2}(\Delta-\delta /)\left(G_{i}^{2}-G_{0}^{2}\right)$ (Figure $7)$. The $D_{\text {c }}$ of $\mathrm{F}_{8} \mathrm{~B}-\mathrm{NCO}$ in the reaction mixture at 60 , 80 , and $100^{\circ} \mathrm{C}$ was determined to be $1.1 \times 10^{-11}, 24 \times$ $10^{-11}$, and $5.3 \times 10^{-11} \mathrm{~m}^{2} \nless$, respectively. As shown in Figure 8 , these data follow an Arrhenius-type behavior

$$
D_{\mathrm{c}}(T)=A \mathrm{e}^{-E_{\mathrm{a}} R T}
$$

where $D_{\mathrm{c}}(T)$ is the $D_{\mathrm{c}}$ at temperature $T, A$ a preexponential, $E_{\mathrm{a}}$ the activation energy, and $R$ the gas constant.

Although it is not possible to measure the $D_{c}$ at a temperature higher than the deblocking temperature (ca. $140{ }^{\circ} \mathrm{C}$ ) of the blocked isocyanates, an estimation of the $D_{\mathrm{c}}$ of $\mathrm{F}_{8} \mathrm{~B}-\mathrm{NCO}$ as it would be at reaction temperatures $\left(150-200^{\circ} \mathrm{C}\right)$ can be obtained by extrapolating the $D_{\mathrm{c}}-T$ curve (Figure 8 ) to higher temperatures, according to (2). The "virtual" $D_{c}$ for $\mathrm{F}_{8} \mathrm{~B}-\mathrm{NCO}$ in the reaction mixture at 150 and $200{ }^{\circ} \mathrm{C}$ (assuming no reaction taking place) would be $25 \times 10^{-10}$ and $8.4 \times$ $10^{-10} \mathrm{~m}^{2} \&$, respectively. Detailed investigations on the competition between the diffusion of fluorinated species and the immobilization of cross-linked networks are under way in our laboratory.

Film Wettability. The value of the contact angle of a liquid on a film is a direct reflection of the surface wettability. Advancing contact angles of water and static contact angles of hexadecane on films based on SLO, $\mathrm{F}_{8} \mathrm{~B}-\mathrm{NCO}$, and $\mathrm{BL}-3272$ as a function of the added fluorine content in the films (calculated from the recipes by assuming complete reactions and no loss of the fluorinated species during heating) are shown in Figure 9. When the films were cured at $200{ }^{\circ} \mathrm{C}$, the water contact angles increased steadily from $87^{\circ}$ to $124^{\circ}$ and the hexadecane contact angles increased from $\mathrm{O}$ (without fluorine present in the films, hexadecane spread over the surface, and a contact angle of $\mathrm{O}$ was assigned) to about $80^{\circ}$, as the added fluorine content in the films increased from $\mathrm{O}$ to $3.8 \mathrm{wt} \%$. The contact angle data 


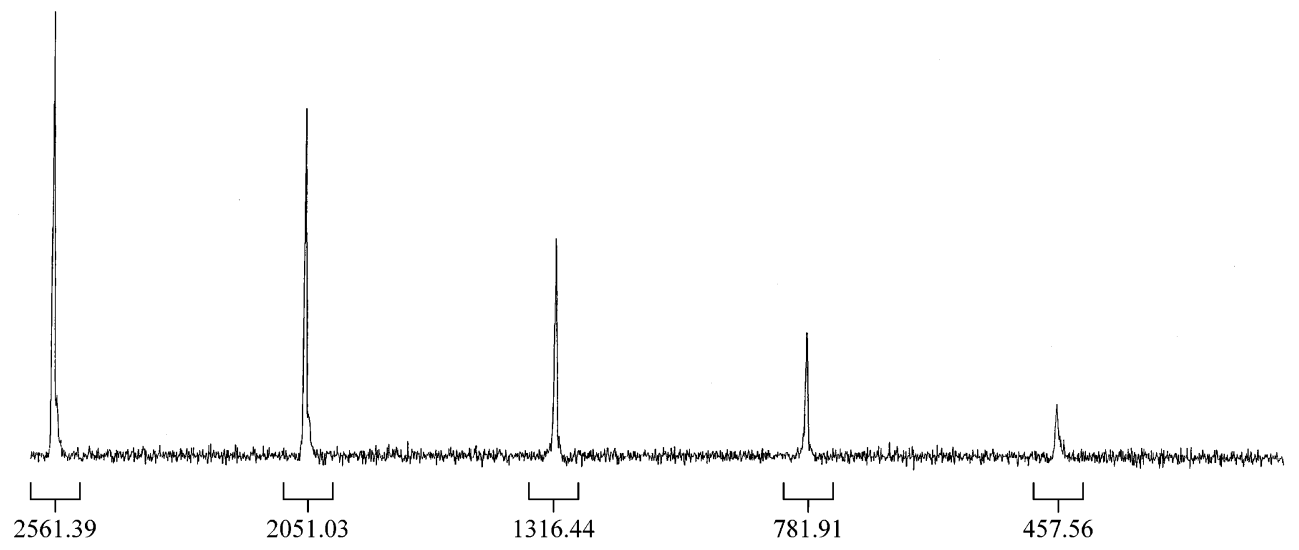

Figure 6 Attenuated signals $S\left(G_{i}\right)$ for a reaction mixture of F 8 B-NCO, SLO, and BL-3272 (containing 3.8 wt \% of F) under increasing field gradients at $100^{\circ} \mathrm{C}$. The applied field gradients $\left(G_{i}\right)$ were (from left to right) $500,10000,17500,25000$, and $32000 \mathrm{~T} m$, respectively. $\Delta=0.40 \mathrm{~s}$ and $\delta=0.001 \mathrm{~s}$.

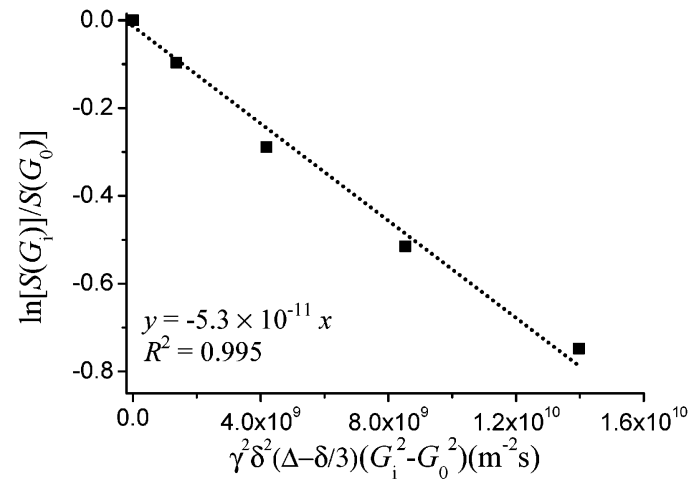

Figure 7. Determination of the $D_{\mathrm{c}}$ of $\mathrm{F} 8 \mathrm{~B}-\mathrm{NCO}$ in the reaction mixture (containing $38 \mathrm{wt} \%$ of $\mathrm{F}$ ) at $100^{\circ} \mathrm{C} ; D_{\mathrm{c}}=5.3 \times 10^{-11}$ $\mathrm{m}^{2} \not$.

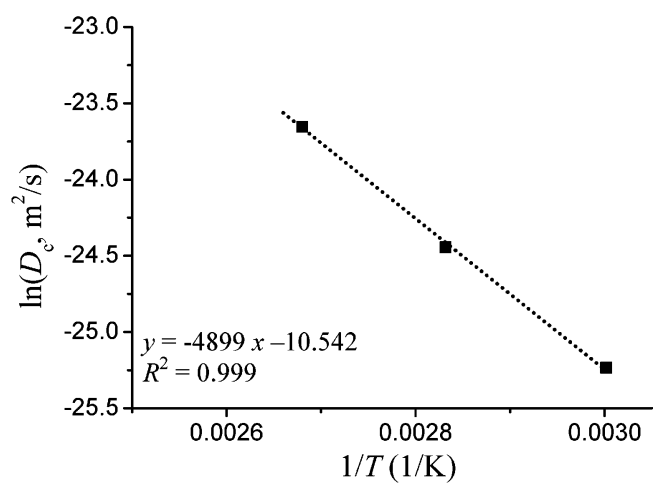

Figure 8. Temperature dependence of the $D_{\mathrm{c}}$ of $\mathrm{F}_{8} \mathrm{~B}-\mathrm{NCO}$ in the reaction mixture.

reached similar levels as in our previous studies in which partially fluorinated nonblocked (poly)isocyanates were used. 5,6 These high contact angles (corresponding approximately to a surface energy of $10 \mathrm{mN} / \mathrm{m}$ ) showed clearly that the surface of the films was significantly enriched in the fluorinated species. 5,6

The low surface energy films were either rinsed by water or rubbed by acetone; the difference of the water advancing contact angles was less than $2^{\circ}$ in comparison with the films as prepared, implying that the fluorinated tail was chemically bonded to the cross-linked films.

On the other hand, when the films were cured at 150 ${ }^{\circ} \mathrm{C}$, the increase of both the water and hexadecane contact angles was much more pronounced upon the addition of a small amount of fluorinated species, as also shown in Figure 9. Both contact angles reached plateau
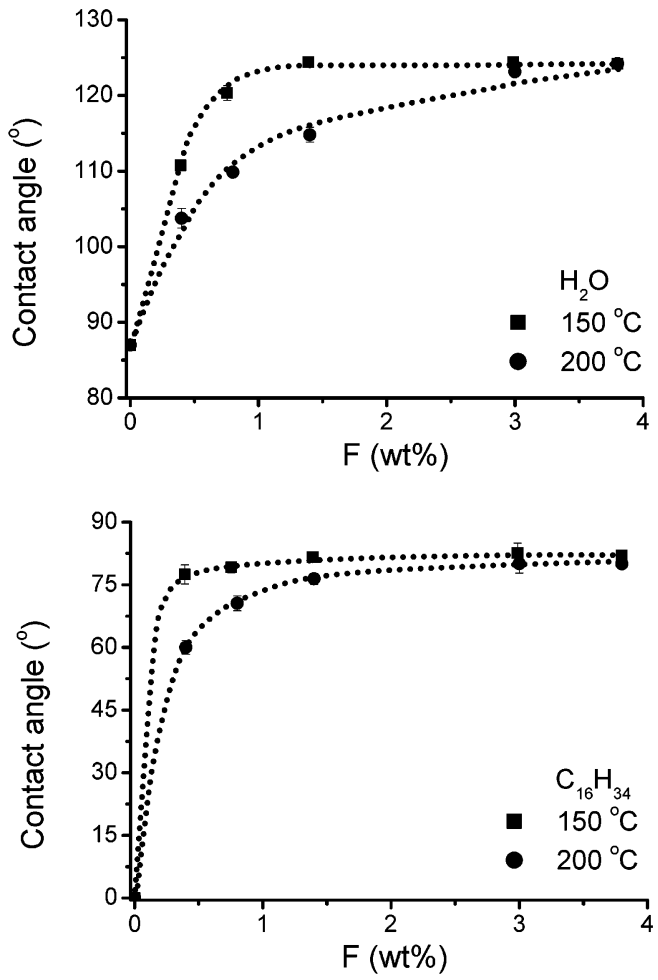

Figure 9. Contact angles of water and hexadecane as a function of the added $\mathrm{F}$ content on the films from SLO, $\mathrm{F}_{8} \mathrm{~B}$ $\mathrm{NCO}$, and BL-3272 cured at 150 and $200^{\circ} \mathrm{C}$, respectively.

values (water: $125^{\circ}$; hexadecane: $80^{\circ}$ ) at lower fluorine concentrations. Further increase of the fluorine content was feasible, which may result in thicker fluorineenriched layers in the surface. ${ }^{15}$ Apparently, when films were cured at a lower temperature, the surface enrichment of the fluorinated species was even stronger. As shown earlier from our FTIR studies in the previous section, the reaction between SLO and BL-3272 proceeded much faster at $180^{\circ} \mathrm{C}$ than at $150^{\circ} \mathrm{C}$. At $200^{\circ} \mathrm{C}$ even less time would be needed for the reaction to be complete. Therefore, at $200{ }^{\circ} \mathrm{C}$ the reactive mixture became immobilized in a very short period of time. The diffusion of fluorinated species would become very limited when the viscosity of the mixture was high. When the mixture was cured at $150^{\circ} \mathrm{C}$, the mixture would remain as a liquid in the first $1 \mathrm{~h}$. Although the diffusion of $\mathrm{F}_{8} \mathrm{~B}-\mathrm{NCO}$ at $150{ }^{\circ} \mathrm{C}$ was about 3 times slower than at $200^{\circ} \mathrm{C}$, as shown by the PFG NMR study, 

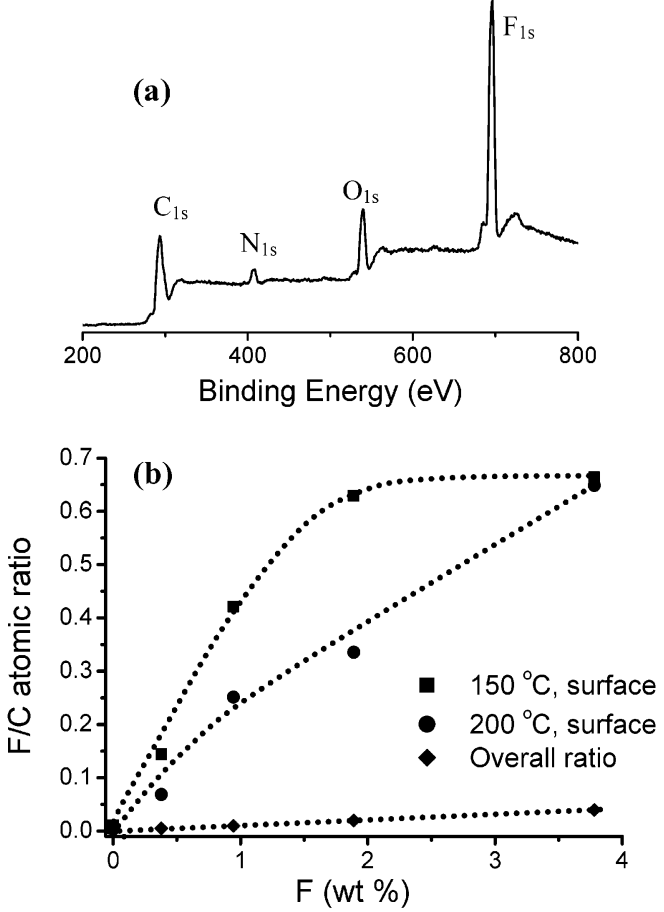

Figure 10. (a) XPS spectrum of a film containing $0.9 \mathrm{wt} \% \mathrm{~F}$ from SLO, $\mathrm{F}_{8} \mathrm{~B}-\mathrm{NCO}$, and BL-3272 cured at $15 \mathrm{O}^{\circ} \mathrm{C}$. (b) $\mathrm{F} \mathrm{C}$ atomic ratio at the surface (about $8 \mathrm{~nm}$ deep) in the films on the basis of SLO, $\mathrm{F}_{8} \mathrm{~B}-\mathrm{NCO}$, and $\mathrm{BL}-3272$ cured at 150 and $200^{\circ} \mathrm{C}$, respectively (the overall $\mathrm{F} C$ ratio was estimated from the recipe of the reaction mixtures).

there was obviously much more time allowed for the fluorinated species to migrate toward the air film interface, leading to the more pronounced surface enrichment of the fluorinated species.

The contact angles on the films from SLO, $\mathrm{F}_{6} \mathrm{~B}-\mathrm{NCO}$, and BL-3272 showed a similar trend to the films from $\mathrm{F}_{8} \mathrm{~B}-\mathrm{NCO}$ as the fluorine content increased, but the plateau values for both water and hexadecane contact angles were lower. Similarly, a higher curing temperature also led to a less significant surface enrichment of the fluorinated species.

Surface Composition at the Film Surfaces. In addition to the contact angle measurements, XPS was used to reveal the fluorine enrichment at the surface. In a typical wide-scan spectrum (Figure 10a), peaks corresponding to $\mathrm{F}_{1 \mathrm{~s}}, \mathrm{C}_{1 \mathrm{~s}}, \mathrm{O}_{1 \mathrm{~s}}$, and $\mathrm{N}_{1 \mathrm{~s}}$ are shown. The $\mathrm{N}_{1 \mathrm{~s}}$ signal was presumably due to the carbamate linkage in the cross-links formed during the film formation (indicated in Figure 4); this signal would be less likely due to the residual $\epsilon$-caprolactam since $\epsilon$-caprolactam was supposed to leave the films during curing. The F C atomic ratio was calculated from the XPS spectra by comparing the $\mathrm{F}_{1 \mathrm{~s}}$ and $\mathrm{C}_{1 \mathrm{~s}}$ peak intensities (in combination with the sensitivity factors for $\mathrm{C}$ and $\mathrm{F}$ ). In Figure $1 \mathrm{Ob}$, the $\mathrm{F} C$ atomic ratio at the surface is given as a function of the added fluorine content in the films on the basis of $\mathrm{F}_{8} \mathrm{~B}-\mathrm{NCO}$. The overall $\mathrm{F} C$ atomic ratio (estimated from the recipes by deducting the amount of $\epsilon$-caprolactam) in the films was lower than 0.04, but in the surface (about $8 \mathrm{~nm}$ deep) of the films much more fluorine-containing species segregated, with the FC ratio reaching 0.65 . The XPS data were in agreement with the contact angle data but showed not exactly the same trend. For the contact angle data, the plateau values were reached at lower F levels than for XPS data. This is reasonable since XPS probes much deeper layers than contact angle measurements. The curing temperature also showed a strong influence on the $F C$ atomic ratio: a lower curing temperature facilitated the surface enrichment of the fluorinated species, especially at a low F content (less than 2 wt \%).

\section{Conclusions}

By using a novel fluorinated blocked isocyanate, together with a conventional blocked polyisocyanate and a hydroxyl-functionalized oligoester, polymeric films with surface energies as low as $10 \mathrm{mN}$ m were readily prepared. The curing temperature demonstrated a significant effect on both the cross-linking reaction and the wettability of the films: a higher curing temperature led to a lesser surface enrichment of fluorine especially at a low $\mathrm{F}$ content (less than $2 \mathrm{wt} \%$ ) because of the fast immobilization of the cross-linked networks. Because of the well-defined $\mathrm{F}_{n} \mathrm{~B}-\mathrm{NCO}$, the fluorine content in the films can be easily and accurately adjusted, making this approach practically attractive and efficient to prepare low surface energy polymeric films by using small amounts of fluorinated species.

Acknowledgment. This study was financially supported by the Dutch Organization for Scientific Research (CW-NWO) and the Graduate School MTCMATTeR at Eindhoven University of Technology. We acknowledge the help from Dr. Marcel van Genderen (TU é) on PFG NMR.

\section{References and Notes}

(1) For example: (a) Grainger, D. W., Castner, D. G., Eds. Fluorinated Surfaces, Coatings and Films, ACS Symposium Series 787; American Chemical Society: Washington, DC 2001. (b) Hougham, G., Cassidy, P. E., Johns, K., Davidson, T., Eds.; Fluoropolymers 1 \& 2 Kluwer Academic Plenum Publishers: New York, 1999.

(2) For example: (a) Schmidt, D. L.; Coburn, C. E.; DeKoven, B. M.; Potter, G. E.; Meyers, G. F.; Fischer, D. A. Nature (London) 199436839 (b) Anton, D. Adv Mater. 199810 1197. (c) Thomas, R. R.; Anton, D. R.; et al. Macromolecules 1997, 30, 2883; Macromolecules 1998 31, 4595; Langmuir 2000, 16, 6898 (d) Ober, C. K.; Kramer, E. J.; et al. Macromolecules 1996, 29, 1229, 1997, 30, 1906; 2000, 33 6106. (e) Castner, D. G.; Grainger, D. W.; et al. J. Am. Chem. Soc. 1996, 118, 1856; J. Fluorine Chem. 2002 115, 107. (f) Mason, R.; Koberstein, J. T.; et al. Adv. Colloid Interface Sci. 2001, 94, 1. (g) Thunemann, A. F.; Lieske, A.; Paulke, B.-R. Adv. Mater. 1999, 11, 321. (h) Ameduri, B.; Bongiovanni, R.; et al. J. Polym. Sci., Polym. Chem. 1999, 37, 77; J. Polym. Sci., Polym. Chem. 2001, 39, 4227; and many others.

(3) Ming, W.; Laven, J.; van der Linde, R. Macromdecules 2000, $33,6886$.

(4) Ming, W.; van Ravenstein, L.; van de Grampel, R.; van Gennip, W.; Krupers, M.; Niemantsverdriet, H.; van der Linde, R. Polym. Bull. (Berlin) 2001, 47, 321.

(5) Ming, W.; Tian, M.; van de Grampel, R. D.; Melis, F.; Jia, X; Loos, J.; van der Linde, R. Macromolecules 2002 35, 6920.

(6) Ming, W.; Melis, F.; van de Grampel, R. D.; van der Linde, R.; et al. Prog. Org. Coat. 2003, 48, 416.

(7) Ming, W.; Lou, X; van de Grampel, R. D.; van Dongen, J. L. J.; van der Linde, R. Macromolecules 2001, 34, 2389.

(8) Loontjens, J. A.; Plum, B. J. M. WO Patent O166633, 2001.

(9) Maier, S.; Loontjens, T.; Boudewijn, S.; Mülhaupt, R. Macromolecules 2003, 36, 4727.

(10) Briggs, D. Surface Analysis of Polymers by XPS and Static SIMS; Cambridge University Press: Cambridge, 1998; Chapter 2 .

(11) Price, W. S. Concepts Magn. Reson. 1997, 9, 299.

(12) Meresi, G.; Wang, Y.; Cardoza, J.; Wen, W. Y.; Jones, A. A.; Inglefield, P. T. Macromolecules 2001, 34, 1131.

(13) Kadi, M.; Dvinskikh, S. V.; Furo, I.; Almgren, M. Langmuir $2002,18,5015$

(14) For example, an excellent review by: Wicks, D. A.; Wicks, Z W., Jr. Prog. Org. Coat. 1999, 36, 148. 
(15) A recent study by dynamic SIMS showed depth-profiling data on fluorinated epoxy films, where the dependence of the thickness (up to $25 \mathrm{~nm}$ ) of fluorine-rich layer on the total fluorine content was clearly demonstrated. See: van Gennip, W. J. H. The Analysis of Polymer Interfaces: A Combined Approach. Ph.D. dissertation, Eindhoven University of Technology, 2003; Chapter 3. Even deeper information ( $\sim 5 \mu \mathrm{m})$ was obtained by DSIMS on fluorinated acrylic polymers recently: Walz, S. M.; Malner, T. E.; Mueller, U.; Muelhaupt, R. J. Polym. Sci., Polym. Phys. 2003 41, 360. On the other hand, depth-profiling information from angular dependence XPS is limited to the top $8-9 \mathrm{~nm}$, as shown in ref 5 , and Schnurer, A. U.; Holcomb, N. R.; Gard, G. L.; Castner, D. G.; Grainger, D. W. Chem. Mater. 1996, \&, 1475.

MA035296I 